\title{
Teaching Reconfigurable Hardware Using an Interdisciplinary Problem Based Model to Strengthen Digital Systems Design Skills in Electronic Engineering Undergraduates
}

\author{
Jorge-Edson Loya-Hernández, José-Luis González-Vázquez, Martha-Isela Garduño-Mota \\ Universidad Autónoma de Baja California, Tijuana, Baja California, MÉXICO \\ jeloyah@uabc.mx,joseg@uabc.mx,mgarduno@uabc.mx
}

\begin{abstract}
This paper presents a course to strengthen Digital Systems Design skills using Reconfigurable Hardware as a tool in a interdisciplinary problem based learning model; system level scenarios allow in-context evaluation of reconfigurable hardware (FPGA) and hardware description language (VHDL) capabilities. The course promotes learning as a constructive, contextual and collaborative process, avoiding the typical isolated technology study. System level design is strengthened throughout the course via problem requirements that define hardware specifications; students' module designs are used to further discuss FPGA and VHDL specific topics.
\end{abstract}

\section{Introduction}

To achieve good Digital Systems Design skills a student needs both digital technology mastering and system level design planning; problem based learning in an interdisciplinary approach offers a variety of opportunities to enhance students experiences and knowledge [1]. VHDL language and FPGA reconfigurable hardware provide both flexibility and technology related limitations that, in a particular context, can promote both skills.

A typical course within the undergraduate engineering program at Universidad Autonoma de Baja California (UABC) Tijuana campus, is structured with lecture and lab sessions. Students are presented with selected materials during lectures, and its usage in an application in lab practices with the purpose to demonstrate these concepts. This course will be implemented during both 2007 semesters and its overall evaluation will be completed by the end of the year.

\section{Digital Systems Design Curricula Background}

The Electronics Engineering (EE) program at UABC offers its students three main tracks: instrumentation and control, communication systems and digital systems (which is in charge of promoting Digital Systems Design skills). Senior year students complement their studies by selecting elective courses, to fulfill 60 required credits from these tracks [2]. Although they have been proposed as focus topics (i.e. to give additional knowledge to their academic curriculum) these tracks have turned into specialization areas. The development of these specialization areas has caused the courses to become isolated from their interdisciplinary context.

Previous planning included reconfigurable hardware incorporation into the curricula, which involved VHDL, PLDs and FPGAs. Circuits developed under academic courses were fairly simple and described only parts of more complex systems [3]. Although proposals were made to implement more complex systems combined in other course tracks, no formal work methodology was developed to take advantage of these tools. A new course was developed under a problem based learning model to continue promoting the use of VHDL and FPGA tools to enhance system design skills within interdisciplinary projects.

\section{Implementation Model}

Curricula goals. Three main features to increase are: system level design skills, team work and technology evaluation criteria. They are achieved when students teams are confronted to solve a problem, promoting generation of a variety of solutions and attending alternative strategies for the application of VHDL skills and use of FPGA's resources. When considering the requirements and restrictions of a system from different perspectives, a student design skills are 
Table 1.- Course Activities Distribution

\begin{tabular}{|c|c|c|c|}
\hline Week & Problem (track) & Activity (module level) & VHDL / FPGA focus topic \\
\hline $1-4$ & $\begin{array}{c}\mathrm{N} / \mathrm{A} \\
\text { (Digital systems) }\end{array}$ & $\begin{array}{l}\text { VHDL introduction. } \\
\text { FPGA description. } \\
\text { Design environment. }\end{array}$ & $\begin{array}{l}\text { VHDL syntax language. } \\
\text { FPGA architecture. } \\
\text { Coding, simulation and synthesis cycle. }\end{array}$ \\
\hline $5-6$ & $\begin{array}{l}\text { Digital voice acquisition } \\
\text { (Communications) }\end{array}$ & $\begin{array}{l}\text { ADC interfacing and control } \\
\text { Sampling rate control } \\
\text { Bandwidth specs }\end{array}$ & $\begin{array}{l}\text { State-machines. } \\
\text { I/O programming (IOBs) }\end{array}$ \\
\hline $7-8$ & $\begin{array}{l}\text { Signal modulation } \\
\text { (Communications) }\end{array}$ & $\begin{array}{l}\text { AM Modulation } \\
\text { DAC Control }\end{array}$ & $\begin{array}{l}\text { Timing control } \\
\text { Frequency division }\end{array}$ \\
\hline 9 & \multicolumn{3}{|c|}{ Final project definition } \\
\hline $10-11$ & PID controller (control) & PID transfer function & Power consumption \\
\hline $12-13$ & $\begin{array}{c}\text { Digital filter } \\
\text { (instrumentation) } \\
\end{array}$ & MAC unit analysis & Layout and placement \\
\hline 14-15 & \multicolumn{3}{|c|}{ Final project development and assessment } \\
\hline 16 & \multicolumn{3}{|c|}{ Final project documentation, presentation and discussion } \\
\hline
\end{tabular}

strengthen in that particular context. When undertaking a problem's solution as a construction on several VHDL subsystems it implies that every student must consider different ways to achieve a goal and identify potential obstacles that they have to take note of. Based on shared experiences obtained form every tried strategy, from every team and exchanging with other teams, collaboration takes a bigger role for generating constructive criticism and distribution of responsibilities within participants.

Course goals. Main goal is teaching VHDL and reconfigurable hardware, on interdisciplinary problem based learning. This is achieved with participation of professors from different areas, with skills to interact in and out of their expertise area. They build scenarios derived from current research topic or professional needed skills, which trigger work within problem context, offering the necessary background so that the problem is understood within that specific scenario.

FPGA technology and VHDL capabilities can be discussed in depth avoiding topics isolation context, requiring collegiate evaluation of students' performance and obtaining model's success indicators.

\section{Course Outline}

Table 1 shows the outline to divide the course activities in a 16 week time frame (course duration).

Once the problem's main topics are reviewed (week 9), instructors will define the final project for each team derived of analyzed scenarios from past weeks, translating it into sub modules that complement the system.

Course evaluation is done through performance of every team/student during group discussion sessions, originality of the solution and also the efficiency during the usage of language and device's resources. A final oral presentation to both students and professors completes the activities.

\section{Conclusions}

This exercise offers students a way to view a problem from different perspectives and assure that, for every scenario, the study variable is examined efficiently and part of the solution is reached fulfilling with the specified problem restrictions. Interaction with specialist from different disciplines (tracks) and the precise definition of the requirements and restrictions are necessary for adequately defining the problem.

The approach also promotes reuse of sub modules in future academic periods to solve more complex problems. Therefore, student's continuity with related topics, as elective courses, participation in research projects, and independent studies are pursued. Finally, it establishes an alternative to extrapolate to other courses within of the EE program.

\section{References}

[1] J. Macías Guarasa, J. M. Montero, R. San-Segundo, A. Araujo, O. Nieto-Taladriz, "A Project-Based Learning Approach to Design Electronic Systems Curricula" in IEEE Transactions on Education, vol. 49, no. 3, August 2003, pp 389-397.

[2] 1994-2 and 2003-1 Electronics Engineering Program. Universidad Autonoma de Baja California, Tijuana, 1994.

[3] N. Bravo, J. Loya, J. Franco, J.L. González "Inclusión de herramientas para dispositivos reconfigurables en la carrera de Ingeniería Electrónica: Experiencias y perspectivas" en Primera Conferencia Internacional de Cómputo Reconfigurable y FPGAs (ReConFig), Tlaxcala, México, Septiembre 2003, pp 163-168. 